\title{
MORFOLOGIA DO FRUTO E DA SEMENTE DE EUTERPE EDULIS, MART. *
}

\author{
Walter Radamés Accorsi \\ Myrthes A. A. de Barros
}

\section{RESUMO}

Estudamos neste trabalho a morfologia do fruto e da semente de Euterpe edulis, Mart., o palmito-doce ou palmito-branco. 0 mesocarpo possui duas camadas de laminas fibrosas, estreitas, inserdas no endocarpo e que diferem entre si pela forma, largura e pouco no tamanho, apresentando a base ramificada por dicotomia. As la minas externas medem $0,5 \mathrm{~mm}$ de largura por $2,3 \mathrm{~cm}$ de comprimento; as internas são mais finas e as últimas são filamentosas. Em sua estrutura, identificamos fibras lenhosas, esclereidos e elementos vasculares espiralados.

Hilo lateral, com forma de canaleta, coberto por um feixe de filamentos fibrosos.

Endocarpo membranoso, mais ou menos consistente, com $0,3 \mathrm{~mm}$ de espessura; nele notamos o hilo, a área opercular com seu operculo, o qual mede $1,8 \mathrm{~mm}$ de diametro. Na estrutura do endocarpo há predominancia de esclereidos sobre as fibras, raramente elementos vasculares ou braquiesclereidos.

Semente globosa, aderente ao endocarpo. Endosperma homogeneo, córneo, com cavidade esférica central e uma cámara cilindrica que abriga o embrião.

Embrião basilar, cilíndrico-cónico, medindo $3,5 \mathrm{~mm}$ de comprimento por 1,8 de diâmetro, possui uma região cônica que corresponde à porção mediana do cotilédone e uma porção cilíndrica que correspnnde à bainha do cotilédone.

$\mathrm{Na}$ germinação, a peça mediana do cotilédone desenvolve em sua extremidade um haustório globoso que digere o endosperma por ação enzimática. Com o aumento de volume, o haustório assemelha-se a um cogumelo.

A bainha invaginante do cotilédone envolve a plúmula e o eixo hipocótílo-radicular. A extremidade da radícula é envolvida por uma coleorriza membranácea e delgada. A plúmula, por sua vez, é envolvida por um coleóptilo de forma cônica, mais espesso e mais resistente que a coleorriza.

- Entregue para publicacăo em 31/12/1974

* Departamento de Botánica da ESALQ. 


\section{INTRODUÇAOO}

0 estudo morfológico do fruto e da semente de Euterpe edulis Mart., constante deste trabalho, resultou de uma pesquisa sobre a germinação da semente de palmito-doce ou palmito-branco, que a Enga. Agra. Maria Elizabete Doni estava conduzindo no Departamento de Agricultura e Horticultura da ESALQ com vistas à preparação de sua dissertação para obtenção do títudo de Mestrado. Sugerimos, então, como complemento de suas investigações, um estudo mais pormenorizado tanto do fruto como da semente e, particularmente, do embrião, uma vez que as descrições existentes sobre tais partes vegetais dizem respeito à Taxonomia.

Assim, JOÃO BARBOSA RODRIGUES (1903) referindo-se ao gênero Euterpe escreve sobre o fruto: "Baga globosa, mais ou menos grande, com resíduos do estígma laterais; epicarpo membranáceo, atro-purpúreo ou verde-purpúreo, branco, cinéreo, tomentoso. Mesocarpo polposo, suculento, purpúreo; endocarpo fibroso membranáceo; semene globosa, e aderente ao endocarpo; hilo lateral, linear, com fibras em forma de agulhas, irradiantes, albumem homogêneo, ou ruminado, córneo, com embrião lateral ou basilar"'.

Segundo GUENJI IAMAZOE (1973), dentre as palmeiras que produzem palmito comestível, apenas as do gênero Euterpe são exploradas comercialmente em larga escala. Entre as espécies, a mais conhecida é a Euterpe edulis, que produz o chamado palmito-branco e é encontrada na região centro e sul do Brasil. No Estado de São Paulo sua ocorrência natural está atualmente confinada na Serra do Mar e Paranapiacaba.

CHADEFAUD e EMBERGER (1960), MCLEAN e IVMEY (1958) tratam de maneira pormenorizada da constituição do embrião e do processo da germinação de algumas espécies de Palmae, de que nos valemos para os estudos que fizemos sobre o mesmo assunto com o Euterpe edulis.

O material estudado proveio do Horto Florestal de Juçara da Cia. Melhoramento Norte do Paraná, e da propriedade Irmãos Tha Ltda., Antonina, Paraná.

\section{MATERIAL E METODO}

Material: o material utilizado no presente trabalho, constituido de frutos, nos foi trazido pela Enga. Agra. Maria Elizabete Doni, do Horto Florestal de Juçara da Cia. Melhoramento Norte do Paraná e, também, da propriedade Irmãos Tha Ltda., de Antonina, Paraná, em julho de 1973.

Os frutos foram colhidos em época própria nas mencionadas regiões, e se encontravam em estado de maturação completa, (inclusive o embrião) e as sementes em condições de germinar. $O$ armazenamento foi feito em sacos plásticos para melhor conservação dos frutos, e, consequentemente, das sementes.

Método: a dissecação para o exame morfológico do fruto e de suas 
partes, epicarpo, mesocarpo, constituido de lâminas fibrosas e dispostas em duas camadas, e endocarpo, bem assim da semente, compreendendo albumem com embrião, foi feito com o auxílio de um binocular Zeiss.

A coloração do material macerado foi feita com safranina aquosa e a montagem em lâminas com geléia e glicerina (fórmula de Kaiser). A mensuração dos elementos do xilema, das fibras e dos esclereidos dos dois tipos de lâminas fibrosas do mesocarpo, foi feita pelo acadêmico Serafim Daniel Ballestero com o auxílio de um microscópio Reichert e ocular micrométrica. Os dados constam do Quadro I.

Apreciamos, também, os aspectos morfológicos do embrião, em vários períodos da germinação. Foram feitos desenhos do fruto e de suas principais partes, da semente e do embrião. Para conhecimento da composição histológica dos dois tipos de lâminas fibrosas do mesocarpo, empregamos a técnica de maceração dos elementos do xilema.

\section{Morfologia do fruto}

Segundo as descrições taxonômicas de Euterpe edulis, Mart. - Juçara, palmito-doce ou palmito-branco, notadamente a de BARBOSA RODRIGUES (1903), o fruto, na maturidade, caracteriza-se por ser "uma baga globosa, mais ou menos grande $(1 \mathrm{~cm}$ de diâmetro), com resíduos do estigma laterais, e às vezes com o perigônio; epicarpo membranáceo, nigro-violáceo. Mesocarpo polposo, suculento, purpúreo; endocarpo fibroso-membranáceo; semente globosa e aderente ao endocarpo; hilo lateral linear, com fibras em forma de agulhas irradiantes, albumem homogêneo, córneo, embrião basilar". Todavia, o exame pormenorizado do fruto seco revela interessantes particularidades morfológicas que a seguir apreciaremos, e que muito contribuirão para o conhecimento da biologia da germinação.

O mesocarpo, que é polposo e suculento no estado de baga, transforma-se em massa ressecada, aderente ao epicarpo e à porção fibrosa do endocarpo. Essa massa seca fragmenta-se facilmente, chegando a pulverizar-se quando se disseca o fruto.

No tocante à natureza fibrosa-membranácea do endocarpo, comprovamos tratar-se não de simples fibras, segundo as descrições mencionadas, mas de camadas de lâminas fibrosas, estreitas, dispostas como se fossem meredianos, cujo conjunto forma o invólucro do endocarpo, dando a aparência de cestinho fibroso. (fig. 2).

As lâminas fibrosas que compõem o invólucro citado se inserem numa região do endocarpo que corresponde, externamente, no epicarpo, à área onde se localizam os resíduos do estígma. A partir da região de inserção, as lâminas fibrosas se dirigem para uma região oposta, onde se situa o opérculo. As lâminas fibrosas diferem entre si na forma, na largura e um pouco no comprimento, (figs. 3 e 4). As mais externas são, frequentemente, lineares, falcatas, com suas extremidades afiladas voltadas para a região do opérculo. A porção basal das lâminas é, geralmente, bifurcada; cada 
ramo, por sua vez, pode bifurcar-se e assim por diante, sendo as ramificações cada vez mais estreitas e delgadas. As últimas ramificações das lâminas se entrelaçam com as correspondentes das lâminas da camada interna ou subjacente e são tão finas, que podem ser consideradas como filamentos fibrosos. Os filamentos fibrosos também se dirigem para o opérculo e suas bases profusamente ramificadas formam com as ramificações basais das lâminas fibrosas externas um trançado bem apertado.

As lâminas fibrosas da camada externa possuem, em média, $0,5 \mathrm{~mm}$ de largura por $2,3 \mathrm{~cm}$ de comprimento. As lâminas da camada subjacente diminuem progressivamente de largura, sendo as últimas filamentosas. Todas, entretanto apresentam as bases bem ramificadas por dicotomia. (Figs. 3 e 4 ).

0 hilo, (fig 6-k) de posição lateral, é linear, assemelha-se a uma canaleta e se extende da região de inserção das lâminas fibrosas, no endocarpo, até a região opercular. Um feixe de filamentos fibrosos, dos mais delgados da camada interna, recobre o hilo em toda a sua extensão. Durante a germinação, esse feixe envolve a parte do embrião que rompeu o epicarpo, alevantando-o.

\section{Estrutura das lâminas fibrosas}

A natureza fibrosa das lâminas foi estudada após a sua maceração, de acordo com a técnica utilizada para o estudo dos elementos do xilema. As lâminas foram, inicialmente, separadas de acordo com o tamanho e a espessura para verificar-se se havia diferenças na composição dos seus elementos.

O exame microscópico do material macerado e colorido revelou a seguinte composição: fibras lenhosas, esclereidos e elementos vasculares espiralados, estes últimos em número e tamanho, bem reduzidos. Não há diferenças qualitativas na composição celular das lâminas externas e internas do invólucro fibroso, mas sim diferenças quantitativas, conforme dados do seguinte quadro: (em micros). 


\section{QUADRO I}

\begin{tabular}{c|c|c|c|c|c}
\multicolumn{2}{c|}{$\begin{array}{c}\text { LARGAS (1. camada) } \\
\text { (comprimento) }\end{array}$} & \multicolumn{3}{|c}{$\begin{array}{r}\text { ESTREITAS (2.a camada) } \\
\text { (comprimento) }\end{array}$} \\
\hline Fibras & Esclereidos & Vasos & Fibras & Esclereidos & Vasos \\
\hline 449,40 & 428,00 & 160,50 & 406,60 & 246,10 & 107,00 \\
599,20 & 337,05 & 197,95 & 374,50 & 214,00 & 112,35 \\
670,89 & 411,95 & 171,20 & 483,64 & 281,41 & 107,00 \\
658,05 & 374,50 & 167,99 & 347,75 & 192,60 & 128,40 \\
481,50 & 438,70 & 165,85 & 377,71 & 272,85 & 114,49 \\
674,10 & 347,75 & & 428,00 & 262,15 & \\
478,29 & 417,30 & & 342,40 & 267,50 & \\
647,35 & 381,99 & & 385,20 & 299,60 & \\
551,05 & 465,45 & & 454,75 & 267,50 & \\
802,50 & 486,85 & & 395,90 & 270,71 & \\
$* 6012,33$ & 4089,54 & 863,49 & 3896,45 & 2574,42 & 569,24 \\
$* * 601,23$ & 408,95 & 172,69 & 389,65 & 257,44 & 113,85 \\
\hline$*$
\end{tabular}

* TOTAL

** MEDIA

\section{Endocarpo}

De natureza membranosa, mais ou menos consistente, com aproximadamente $0,3 \mathrm{~mm}$ de espessura, adere intimamente à semente, que é de forma esférica. Removendo-se as lâminas fibrosas, aparece na superfície do endocarpo o hilo linear (fig. 6-k), como pequena depressão, extendendo-se da região de onde se irradiam as lâminas até a área opercular; esta se apresenta como uma depressão circular do endocarpo, em cujo fundo está o opérculo, (fig. 5-g).

Durante a germinação e devido à pressão do embrião em crescimento, o opérculo destaca-se como uma tampa circular, que mede $1,8 \mathrm{~mm}$ aproximadamente, de diâmetro, (fig. 5-g).

A composição histológica do endocarpo é mais simples que a das lâminas fibrosas que o revestem. Procedendo-se à maceração, verifica-se que há predominância de esclereidos em relação às fibras, havendo, ainda, elementos que lembram os braquiesclereidos. Raramente encontram-se elementos vasculares espiralados. As mensurações em micros dos esclereidos e fibras figuram no quadro adiante: 


\begin{tabular}{|c|c|}
\hline ESCLEREIDOS & FIBRAS \\
\hline 278,20 & 310,30 \\
\hline 224,70 & 465,45 \\
\hline 214,00 & 374,50 \\
\hline 272,85 & 379,85 \\
\hline 232,19 & 433,35 \\
\hline 240,75 & 235,40 \\
\hline 278,20 & 321,00 \\
\hline 242,89 & 385,20 \\
\hline 197,95 & 321,00 \\
\hline 267,50 & 424,79 \\
\hline TOTAL $\quad 2449,23$ & 365,08 \\
\hline MEDIA $\quad 244,92$ & 3650,84 \\
\hline
\end{tabular}

\section{Morfologia da semente}

\section{Endosperma}

Como mencionamos, a semente do palmito-doce caracteriza-se por ser globosa e aderente ao endocarpo; endosperma homogêneo, córneo, (figs. 7 e 8).

Na região central, o endosperma apresenta uma cavidade esférica que se origina, segundo se deduz, durante a formação da semente. Além dessa cavidade central, existe no endosperma uma câmara cilíndrica que contém o embrião, a qual se comunica ao curtíssimo canal opercular, fechado pelo opérculo, (fig. 7-n).

\section{Embrião}

0 embrião, cilíndrico-cônico, de posição basilar na semente, mede $3,5 \mathrm{~mm}$ de comprimento, por $1,8 \mathrm{~mm}$ de diâmetro, (fig. 5 -h). A porção cônica, esbranquiçada, de $2,3 \mathrm{~mm}$ de comprimento, corresponde à peça mediana do cotilédone, (fig. 5-j). A porção cilíndrica, marrom, voltada para o opérculo, mede $1,2 \mathrm{~mm}$ de comprimento, por $1,8 \mathrm{~mm}$ de diâmetro, corresponde à bainha do cotilédone, (fig. 5-i). A base da porção cilíndrica em contacto com o opérculo traz a impressão do próprio opérculo.

Ao se dar a germinação, a peça mediana do cotilédone desenvolve em sua extremidade um haustório globoso, que digere o endosperma através 
da produção de enzimas, assumindo a forma de cogumelo, à medida que vai aumentando de volume, (figs. 7 e 8-0).

A bainha invaginante do cotilédone envolve a plúmula e o eixo hipocótilo-radicular. Ela corresponde, no embrião, à porção cilíndrica já citada. Durante a germinação, após empurrar o opérculo, ela atravessa o canal opercular e expande-se em sentido perpendicular ao eixo cotiledonar; a princípio, permanece coberta pelo envoltório das lâminas fibrosas do endocarpo e pelo epicarpo. Nesse estádio, assume a forma de um cilindro pouco inflado em sua região central, com dois polos mais ou menos cônicos, contendo, respectivamente a plúmula e a radícula, (fig. 7-q). A radícula é a primeira a romper a porção da bainha cotiledonar que a envolve, cujos bordos permanecem aderentes à sua base, (fig. 8-s). A radícula está envolvida por uma coleorriza, de natureza membranácea, bem delgada, (figs. 8 e 9-t). A coleorriza desprende-se, por sua vez, da base permanecendo na extremidade da radícula como um capuz, (fig. 9-t). Ela acompanha o crescimento da radícula. A seguir, raízes adventícias brotam no hipocótilo bem próximas à base da radícula e são de crescimento mais rápido do que ela. Raízes de segunda ordem vão nascendo das raízes adventícias, (fig. 9-r).

$O$ outro polo, por sua vez, fende-se, formando uma abertura circular, por onde passa a plúmula (fig. 9-v). A plúmula está envolvida por um coleóptilo de forma cônica, sendo mais espesso e mais resistente do que a coleorriza; também se desprende pela base, em virtude do crescimento da plúmula, (figs. 8 e 9-u). mente.

Desse estádio em diante, o «seedling» cresce e se desenvolve, normal-

\section{SUMMARY}

MORPHOLOGY OF FRUTTS AND SEEDS OF EUTERPE EDULIS MART. Mart.

This paper describes the fruit and seed morphology of Euterpe edulis,

The mesocarp has fibrous blade, with $0,5 \times 23 \mathrm{~mm}$ in average, made of wood fibers, sclereids and spiralated vessels.

Endocarp membranous, 0,3 $\mathrm{mm}$ thick, with predominancy of sclereids over fibers, lateral hilum, excavated. Opercular area, and operculum with $1,8 \mathrm{~mm}$ of diameter.

The basal embryo, with cylindrical-conic shape has $3,5 \mathrm{~mm}$ length and $1,8 \mathrm{~mm}$ in diameter. It has two regions, one conic and the other cylindrical. They correspond respectively to the median part and to the sheath of the cotyledon. The firts one develops during the germination in haustorium, and the second enclosed the plumule and the hypocotyl-root axis. The radicle is enclosed by the coleorhiza and the plumule by an coleoptile. 


\section{LITERATURA CITADA}

BARBOSA RODRIGUES, J., 1903 - Sertum Palmarum Brasiliensium. Imprimerie Tipographique Veuve Monnom. Bmixelles.

CHADEFAUD, M. e EMBERGER, L., 1960 - Traité de Botanique Systematique, Tame I. Masson et Cie. Editeurs, Paris.

IMAZOE, G., 1973 - Observações preliminares sobre a cultura de Euterpe edulis, Mart. Editado pela Secretaria da Agricultura do Estado de São Paulo, Coordenadoria da Pesquisa de Recursos Naturais, Instituto Florestal, Boletim Técnico n.` 6.

MCLEAN, R. C., e IVIMEY-COOK, W. R., 1958 - Textbook of Theoretical Botany, vol. two. Longmans, Green and Co, London. New York. Toronto. 


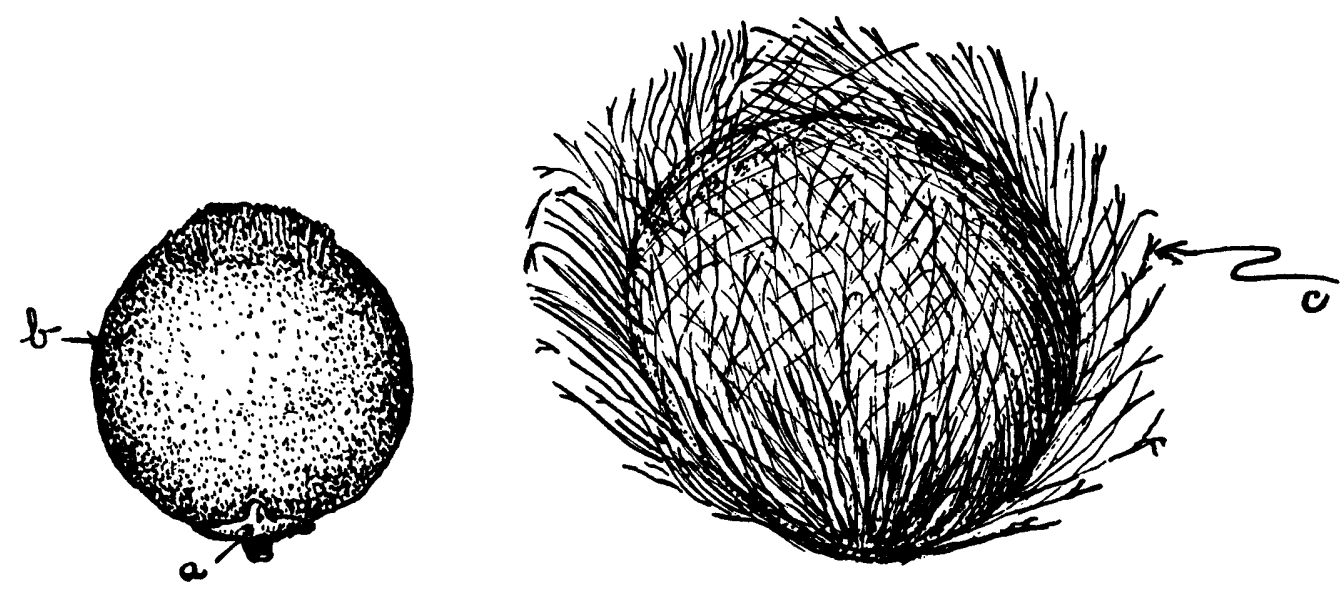

Fig. I (3x)

Fig. $2(4,5 x)$
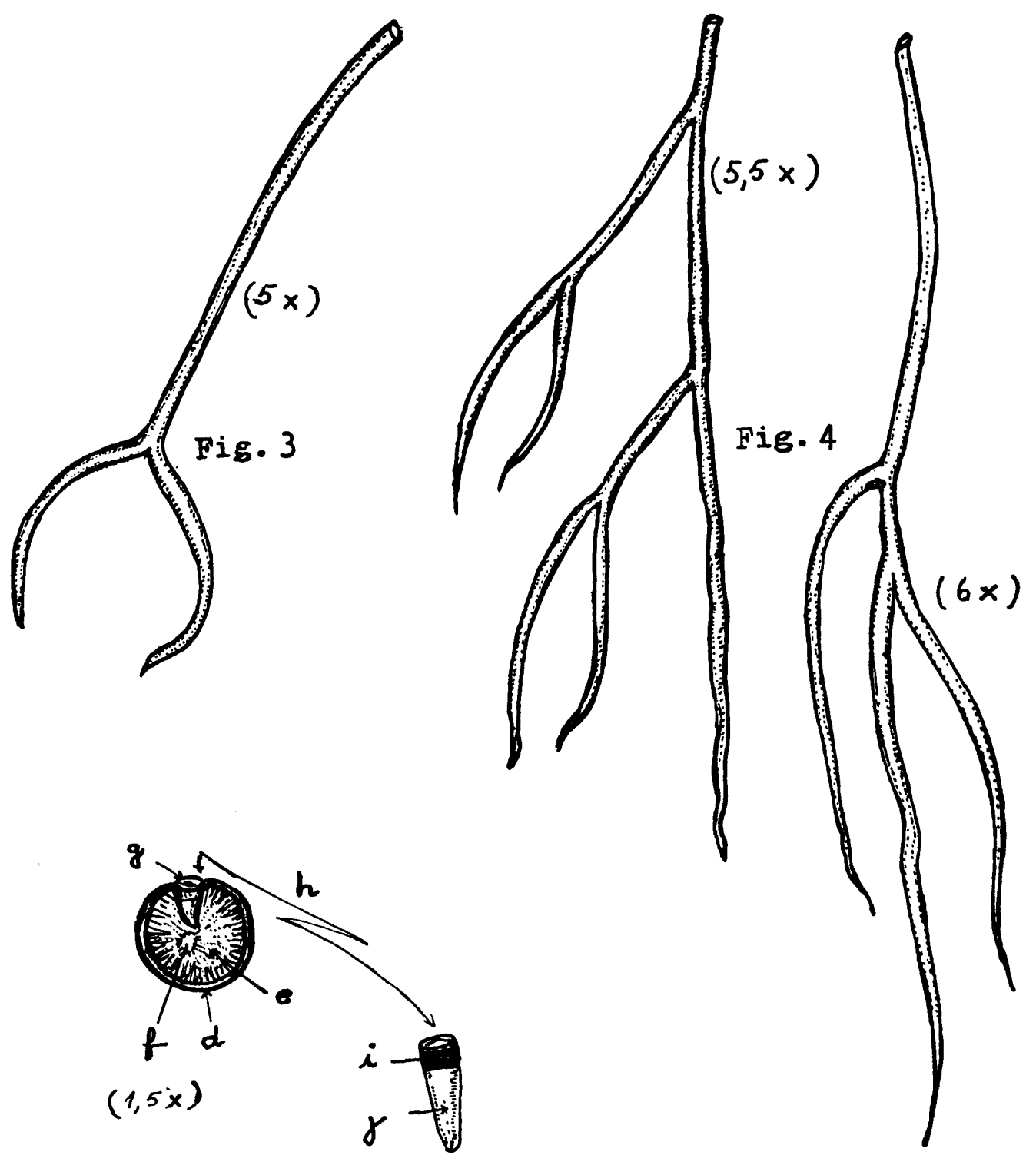

Fig. 5 


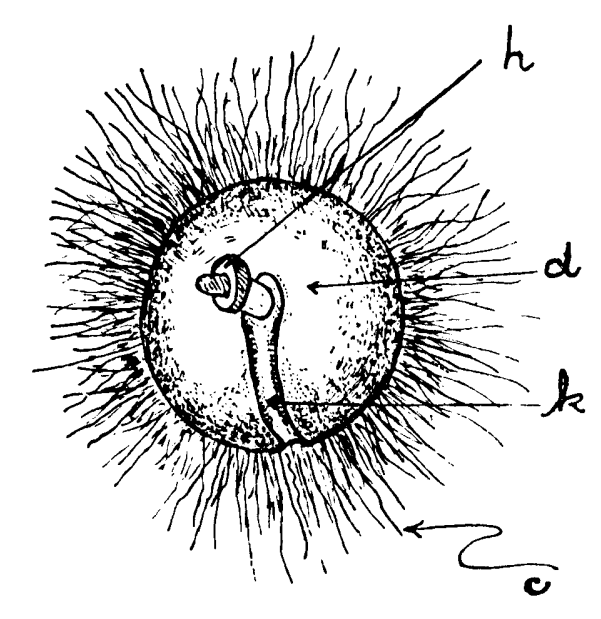

$P=.6(3 x)$
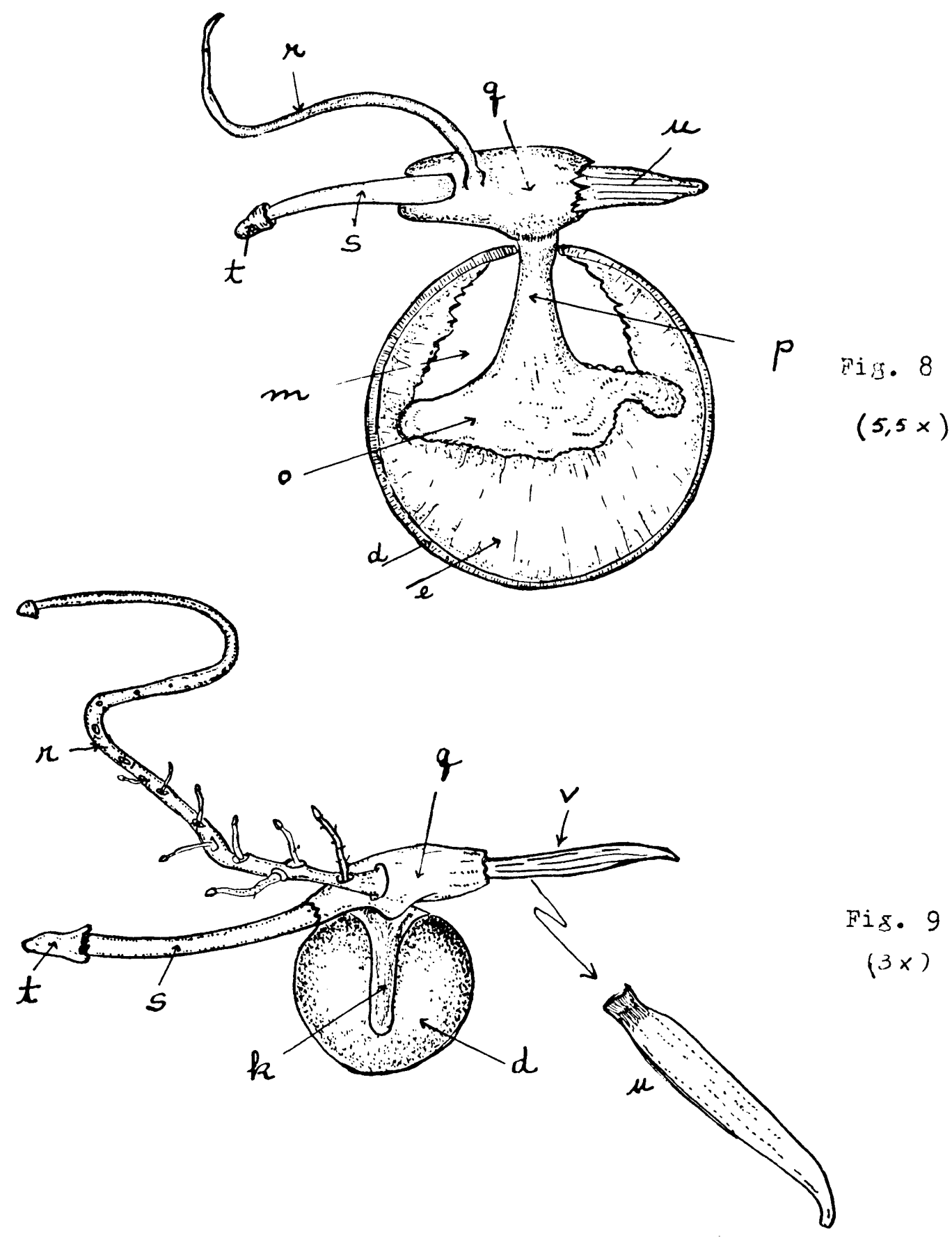

Fis. 9

$(3 \times)$ 


\section{LEGENDA}

Figura 1 - Fruto completo (seco)

Figura 2 - Fruto sem o epicarpo

Figuras 3 e 4 - Lâminas fibrosas de comprimento e formas diferentes

Figura 5 - Corte do fruto e da semente

Figura 6 - Fruto

Figura 7 - Fruto e semente (corte)

Figura 8 - Fruto e semente em corte. Embrião.

Figura 9 - Fruto e embrião em desenvolvimento.

Em todas as figuras:

a - perigônio

b - epicarpo

c - lâminas fibrosas inseridas no endocarpo.

$\mathrm{d}$ - endocarpo

e - endosperma córneo

f - cavidade central do endosperma. (início).

$\mathrm{g}-$ opérculo

h - embrião cilíndrico-cônico

i - porção cilíndrica do embrião

$\mathrm{j}$ - porção cônica do embrião

$\mathrm{k}$ - hilo excavado no endocarpo

1 - mesocarpo com lâminas fibrosas

$\mathrm{m}$ - cavidade central do endosperma ampliada por ação enzimática.

n - câmara do embrião, no endosperma

o - haustório em forma de cogumelo.

$\mathrm{p}$ - peça mediana do cotilédone.

q - bainha do cotilédone, envolvendo o embrião

$\mathbf{r}$ - raiz adventícia

$\mathrm{s}$ - radícula

$\mathrm{t}$ - coleorriza

$\mathrm{u}$ - coleóptilo

$\mathrm{v}$ - plúmula.

Desenhos originais confeccionados pela Doutora Myrthes A. Adâmoli de Barros. 
